\title{
UTILIZAÇÃO DE RECURSOS TECNOLÓGICOS EM ATIVIDADES DE PRODUÇÃO DE TEXTO ORAL NO LIVRO DIDÁTICO DE PORTUGUÊS
}

\author{
Guilherme Arruda do EGITO* ${ }^{1}$ \\ Edmilson Luiz RAFAEL $*^{2}$
}

\begin{abstract}
Resumo: Este artigo objetiva discriminar as atividades de produção de texto oral em função de seus objetivos em três coleções de livros didáticos e identificar os recursos tecnológicos necessários à realização das atividades. A pesquisa se insere nos pressupostos qualitativos da linguística aplicada e é do tipo documental. Como resultados, foi possível verificar que os recursos gravador, filmadora e smartphone foram solicitados para utilização nas atividades ora mencionadas de forma nuclear ou periférica. Ao sugerir que esses recursos sejam utilizados, as atividades se direcionam para o paradigma da complexidade, pois exigem do aluno a mobilização de conhecimentos que não apenas linguísticos para a sua realização.
\end{abstract}

Palavras-chave: Livro didático. Recursos tecnológicos. Ensino de língua.

\begin{abstract}
This paper aims to investigate reading activities and textual production activities towards its objectivies in tree collection textbooks and to identify the technological resources necessary in the performance of these activities. The research is inserted in the qualitative assumptions of Applied Linguistics and is of the documentary type. As a result, it was possible to verify that the recorder, camcorder and smartphone resources were requested for use in the aforementioned activities in a nuclear or peripheral way. In suggesting that these resources be used, the activities are directed towards the paradigm of complexity, since they require the student to mobilize knowledge that is not only linguistic in its realization.
\end{abstract}

Keywords: Textbooks. Technological resources. Language teaching.

\section{Introdução}

Objeto de inúmeras pesquisas (BUNZEN, 2009; DIONÍSIO e BEZERRA, 2005; ROJO e BATISTA, 2003; entre outros), o Livro Didático de Português (doravante, LDP) tem um importante papel no desenvolvimento educacional dos alunos pois esse instrumento, além de ser a primeira plataforma de ensino a distância (CORTELLA, 2014, p. 52), representa para a maioria dos professores o único suporte para a propagação de conhecimentos especializados sobre linguagem, dos mundos impresso e virtual, para muitos indivíduos brasileiros no nível de formação escolar básica.

Esse instrumento apresenta em seu projeto de ensino diversas situações e atividades escolares envolvendo o uso de recursos tecnológicos digitais, como produzir e gravar uma entrevista ou debate com o uso de uma filmadora, ler textos com vídeos educativos e realizar pesquisas escolares com o computador, entre outras situações.

Pudemos confirmar esta afirmação em estudos por nós realizados ${ }^{3}$, no âmbito da Linguística Aplicada (doravante, LA), em um período de três anos (2013-2016). Na primeira

\footnotetext{
${ }^{1}$ Mestrando do Programa de Pós-Graduação em Linguagem e Ensino (POSLE/UFCG). Endereço: Rua Aprígio Veloso, 882 - 58429-900 - Campina Grande - PB - Brasil. Telefone: 083991066954. E-mail: guilhermeegito@gmail.com.

${ }_{2}$ Professor doutor do Programa de Pós-Graduação em Linguagem e Ensino (POSLE/UFCG). Endereço: Rua Aprígio Veloso, 882 - 58429-900 - Campina Grande - PB - Brasil. E-mail: eluizrafael@ gmail.com.

3 Estes estudos foram desenvolvidos durante a graduação no âmbito dos projetos de pesquisa Formas de utilização de tecnologias em livros didáticos de português (2013-2014), Orientações para utilização de
} 
etapa da pesquisa, o interesse foi verificar os recursos mobilizados em LDP e de que forma essa mobilização ocorre. Para isso, necessitávamos identificar em três coleções de LDP do ensino fundamental, recomendadas pelo PNLD, os tipos desses recursos e a sua forma de utilização em relação ao tipo de atividade proposta ao aluno.

Como resultados, constatamos que o uso da tecnologia gráfica é predominante, representada pela utilização de livros como suporte principal, para mobilização de textos escritos, integrais ou fragmentos, de diversos gêneros. $\mathrm{O}$ computador aparece em segundo lugar, principalmente como recurso para consulta e buscas em sites da internet. Em terceiro lugar, outros recursos como DVD e CD são apresentados, geralmente, com a mesma função do computador. Quanto à mobilização desses recursos, constatamos que, de forma geral, se destina na maioria das vezes para as atividades de leitura a serem realizadas pelo aluno (EGITO e RAFAEL, 2014).

Observando ainda o interesse da pesquisa realizada, percebemos a necessidade de sua continuação para investigar a utilização dos recursos em situações mais concretas, o que nos levou a focar as atividades de leitura e de produção textual dirigidas aos alunos. Nesta segunda etapa, percebemos que tais atividades têm o objetivo de levar o aluno a conhecer a temática de discussão de cada uma das unidades dos LDP ou o gênero textual trabalhado, além de produzir textos relacionados a eles, mobilizando na realização destas atividades diversos recursos, sobretudo o computador e o gravador (EGITO e RAFAEL, 2016).

Da leitura conjunta dessas duas etapas, voltadas para o livro do aluno, empreendemos esforços para a terceira etapa da pesquisa, voltada para o Manual do Professor (doravante, MP), em que o interesse foi saber que orientações eram destinadas pelas coleções aos professores quanto ao uso de recursos tecnológicos para o ensino de língua portuguesa. Como resultado (EGITO e RAFAEL, 2015), verificamos nos MP dos LDP um predomínio de orientação teórica sobre o objeto de ensino (a língua), ficando o fazer metodológico, o que inclui a utilização dos recursos tecnológicos, para o componente do planejamento do professor.

A partir desses resultados, realizamos um recorte para este trabalho em que nos interessou analisar especificamente as atividades de produção de texto oral a partir do seguinte questionamento: que formas de utilização de recursos tecnológicos digitais estão subjacentes às atividades de produção de texto oral dirigidas aos alunos nos anos finais do ensino fundamental?

Tendo em vista responder a essa questão, dois objetivos específicos guiaram as ações de pesquisa: 1) discriminar as atividades de produção de texto oral em função de seus objetivos; 2) identificar os recursos tecnológicos necessários à realização das atividades para além do LDP.

Dessa forma, além da continuidade da investigação, o interesse por este estudo justifica-se por refletir sobre materiais que são de interesse do professor em atuação na educação básica, contribuindo para um conhecimento mais aprofundado em torno das relações entre tecnologia, recursos didáticos e ensino de língua.

Para este trabalho, foram utilizadas três coleções de LDP dos $3^{\circ}$ e $4^{\circ}$ ciclos do ensino fundamental. Tais coleções que constituem o corpus desse trabalho foram utilizadas em

tecnologias em manuais do professor de livros didáticos de língua portuguesa (2014-2015) e Recursos tecnológicos em atividades de leitura e de produção textual nos anos finais do ensino fundamental (2015-2016), todos vinculados ao Programa Institucional de Bolsas de Iniciação Científica (PIBIC/CNPq/UFCG) e ao grupo de pesquisas Teorias da Linguagem e Ensino (UFCG). Além destes projetos de pesquisa, também foi importante para a construção do texto deste trabalho as discussões realizadas no âmbito do projeto Novas configurações de ensino de leitura e escrita em atividades de linguagem(ns) (2014-2017), coordenado pelos Profs. Dra. Williany Miranda da Silva (POSLE/UFCG) e Dr. Edmilson Luiz Rafael (POSLE/UFCG). 
escolas públicas da educação básica de Campina Grande-PB e recomendadas pelo guia do PNLD 2014.

Quanto à organização, esse trabalho está dividido em quatro partes, além desta introdução. Na primeira, explicitamos os princípios teóricos adotados; na segunda, descrevemos os aspectos metodológicos da pesquisa; na terceira apresentamos a análise do corpus e na quarta parte fizemos as considerações finais desse trabalho.

\section{teóricas \\ 2. O ensino de língua portuguesa em contexto tecnológico: considerações}

Este item apresenta os aportes teóricos desta pesquisa e está organizado em duas partes: Atividades escolares de produção de texto oral e Recursos tecnológicos e planejamento de ensino. Tal organização se propõe a discutir e a compreender fenômenos que estão em evidência nos LDP com base em reflexões teóricas advindas da LA e da educação sobre ensino de língua (MATENCIO, 2001), formação docente (FREIRE e LEFFA, 2013; LUCKESI, 2011) e recursos tecnológicos (KENSKI, 2012) em conformidade com as políticas nacionais de ensino para o nosso interesse de pesquisa.

\subsection{Atividades escolares de produção de texto oral}

A partir do final do século XX, o ensino de língua portuguesa no Brasil tem se ajustado em torno dos eixos da leitura, produção de textos (orais e escritos) e análise linguística. Tal reconfiguração no funcionamento do ensino aconteceu em virtude de diversos estudos (GERALDI, 1984; 1991) proporcionados pela LA que passaram a circular na comunidade acadêmica e especialmente com a apresentação dos Parâmetros Curriculares Nacionais (PCN) ao sistema escolar brasileiro em 1998.

No caso do eixo da produção de textos (escritos e orais), o ensino de língua portuguesa deve contribuir para a proficiência dos alunos e a formação de indivíduos capazes de participarem de diversas situações comunicativas. Entretanto, o trabalho com este eixo de ensino não pode se limitar apenas aos textos escritos, sendo necessário que se promova em sala de aula situações capazes de desenvolver nos alunos a habilidade do planejamento de textos orais para apresentações públicas, como debates, entrevistas, reportagens etc.

Estes gêneros orais entram no cotidiano escolar principalmente através do LDP como importante instrumento de uso e de reflexão sobre a linguagem, colocando o aluno em situações de exercício de inúmeras práticas sociais. Nesta perspectiva, de acordo com os PCN (1998, p. 25) e a Base Nacional Comum Curricular (2015, p. 39), o que está em foco não é o treinamento do aluno para o uso desses gêneros, mas a sua capacitação para o uso e a prática de cada um deles com o objetivo de torná-lo um usuário competente da língua para além dos limites do espaço escolar. Além disso, esse objetivo contribui para que o aluno desenvolva habilidades interativas no momento da produção desses gêneros, sempre refletindo sobre o desenvolvimento de sua autonomia na prática deles.

No entanto, ainda hoje estes gêneros têm sido menos explorados em relação aos gêneros escritos, mostrando que os últimos são mais privilegiados na sala de aula, ao invés de se propor atividades que demonstrem diferenças e semelhanças entre a linguagem oral e escrita, e entre as diversas variantes que nelas se apresentam, e que ambas pressupõem as suas condições de produção e a prática do planejamento para a produção dos textos.

Com a intenção de romper com esta prática é que diversos estudos em LA (LINO DE ARAÚJO e SILVA, 2013; MARCUSCHI, 2003; SCHNEUWLY e DOLZ, 2004; entre outros) e o PNLD têm se esforçado para que as produções de textos orais sejam mais incorporadas às aulas de língua portuguesa de forma eficaz, com a devida preparação para sua 
realização, eliminando preconceitos associados às variedades e gêneros orais, como os de que os gêneros escritos são mais importantes que os orais ou que os gêneros orais servem como pretexto para o ensino de um gênero escrito nas atividades escolares, entre outros.

Este conceito de atividades, de inspiração psicológica (LEONTIEV, 1983), e de grande importância nesta pesquisa, transita entre as áreas da educação e da LA, para as quais o seu conceito e a sua utilização assume uma posição estratégica quando o tema é ensino. Nesta pesquisa, partilhamos da definição proposta por Matêncio (2001, p. 88), para quem atividades são "operações de ensino-aprendizagem complexas, englobando ao mesmo tempo várias sequências didático-discursivas”, ou tarefas, para realizá-las.

Estas ponderações nos mostram que as atividades de produção de texto oral, assim como as de texto escrito, pressupõem ações didáticas que exigem o envolvimento dos sujeitos no planejamento, com vistas à adequação do texto ao contexto em que ele funciona, colocando "o objeto de ensino em redes de práticas, instrumentos e instituições que lhe dão sentido no mundo social" (SIGNORINI, 1998, p. 13). Cabe ao LDP, por exemplo, com esta finalidade, propor atividades de produção de textos orais que mobilizem práticas sociais que potencialmente estejam mais próximas do aluno ou que sejam necessárias à sua participação na sociedade como um sujeito capaz de reivindicar seus interesses.

\subsection{Recursos tecnológicos e planejamento de ensino}

As atividades escolares de leitura e de produção de textos da atualidade demandam em suas práticas recursos que não apenas o papel e a caneta em suas realizações. Recorrentemente temos observado a necessidade de se realizar a leitura e a produção de textos no espaço escolar com o uso do computador, smartphone, tablet, entre outros recursos similares à funcionalidade e exigência dos textos ora apresentados.

Signorini (2007, p. 218) considera o uso desses recursos como constituintes da inovação, principalmente pelo seu caráter contextual e dinâmico. Contextual porque eles estão presentes em diferentes práticas escolares e não-escolares do público juvenil, o que imprime também um caráter motivacional, e dinâmico por oferecer outras possibilidades de materiais didáticos ao ensino que não o papel e a caneta.

Dessa forma, respeitados os limites da nossa reflexão, nos apropriamos do conceito de recursos tecnológicos proposto por Kenski (2012), para quem estes recursos são objetos de natureza técnica produzidos pelo homem para trazer mais facilidades na vida das pessoas em atendimento a fins específicos. Desse ponto de vista, tanto o LDP quanto qualquer outro material utilizado como apoio técnico na realização de ações de ensino são recursos tecnológicos, tendo em vista que trazem mais facilidades e atendem a um interesse específico que é o ensino de língua portuguesa.

A avaliação a respeito do que nos mostra Signorini (2007), trazendo para a discussão os recursos como representantes da inovação, indica uma perspectiva de ensino em que o cerne das atividades escolares desloca-se do paradigma tradicional (KUHN, 1996), que entende o conhecimento de forma estável, homogênea e cristalizada, para o paradigma emergente (MORAES, 1997), sistêmico (VASCONCELOS, 2002) ou da complexidade (FREIRE e LEFFA, 2013), entendendo-as como um processo dinâmico, suscetível às peculiaridades do contexto em que se realiza, aos recursos que lhe dão suporte para sua materialização e dos sujeitos que irão utilizá-los em suas práticas sociais e escolares (RAFAEL, 2017).

Para Freire e Leffa (2013), o paradigma da complexidade põe em discussão a instabilidade, a dinamicidade e a flexibilidade como fatores que se interconectam, transformam e agem sobre o conhecimento em diferentes atividades processuais que envolvam seus sujeitos, neste caso, aluno e professor, e os seus ambientes de formação. Neste 
paradigma não há espaço para a repetição de práticas consideradas tradicionais, como a reprodução de conhecimento, mas de um lugar decisivo para a aprendizagem e sobre como os seus sujeitos pensam e agem, práticas altamente reflexivas no contexto docente.

O componente principal desta discussão é o do planejamento de ensino que atua como mecanismo de condução da operacionalização das atividades, projetando os fins e estabelecendo os meios que se deve alcançar ao término de uma atividade (LUCKESI, 2011), orientando a sua realização. Nesse momento, os professores atualizam os seus saberes que serão apresentados em sala de aula através de relações entre o saber-fazer e o fazer-saber (TARDIF, 2014) no momento da transposição didática, o que torna essa discussão ainda mais complexa.

\section{Aspectos metodológicos da pesquisa}

Neste item são apresentados os aspectos metodológicos da pesquisa, organizados da seguinte forma: primeiro são definidos o tipo e a natureza da pesquisa e em seguida é descrito o corpus analisado.

\subsection{Tipo de pesquisa}

Tendo em vista o crescente número de estudos voltados para o ensino-aprendizagem de língua portuguesa, proporcionados em grande parte pela Linguística Aplicada (doravante, LA), muitas pesquisas têm se voltado para a necessidade de descrever e analisar materiais didáticos (BUNZEN, 2009; DIONÍSIO e BEZERRA, 2005; ROJO e BATISTA, 2003; entre outros), especificamente o LDP, como é o caso desse trabalho.

A LA é uma ciência de estudos da linguagem em pesquisas interdisciplinares (MOITA LOPES, 2013) em diversificados contextos interacionais. Em interface com a educação, essa área sempre esteve identificada com pesquisas voltadas para a preparação e avaliação de materiais didáticos (CELANI, 2000, p. 29-30), compreendendo-os como indispensáveis para o trabalho do professor e aprendizagem do aluno.

Para este trabalho, essa perspectiva interdisciplinar da LA envolve uma pesquisa de abordagem qualitativa do tipo descritivo-interpretativista (MOREIRA e CALEFFE, 2008) de natureza documental (LE GOFF, 1990), visto que o LDP é um documento oficial de ensino legitimado pelo Ministério da Educação através das avaliações do PNLD.

\subsection{Descrição dos LDP selecionados}

De acordo com Bunzen e Rojo (2005, p. 86), o LDP tem o propósito de "re(a)apresentar, para cada geração de professores e estudantes, o que é oficialmente reconhecido ou autorizado como forma de conhecimento sobre a lingua(gem) e sobre as formas de ensino-aprendizagem". Esses conhecimentos que se referem aos eixos de ensino da língua (leitura, produção de textos e análise linguística) encontram-se organizados em formas ou estruturas diferenciadas, de acordo com o projeto autoral de cada LDP, como veremos mais a diante.

Para esta análise contemplamos três coleções de LDP distintas, às quais estamos chamando genericamente de A, B e C. Nessas três coleções encontramos propostas de atividades de produção de textos orais que mobilizam o uso de recursos tecnológicos.

Os LDP analisados de modo geral apresentam um layout atraente, com uma diagramação que envolve diversos textos, gráficos, infográficos e imagens bem elaborados em diversas cores, letras e estilos. Além disso, os LDP observados se distanciam de uma perspectiva teórica que percebe o texto como um produto pronto e acabado e assumem uma 
concepção de linguagem com vistas ao processo sócio-interativo (BRONCKART, 2008), que compreende o texto dentro de uma prática social situada, levando em consideração a ação e a interação dos sujeitos, os seus objetivos, suas condições de produção e o domínio do código linguístico.

Cada volume da Coleção A tem em média 270 páginas e apresenta quatro unidades. Cada unidade possui um eixo temático que orienta a apresentação dos textos (em diversos gêneros) e diversas seções. Entre as seções mais frequentes estão: Estudo dos textos, Produção de texto, Para escrever com expressividade, A língua em foco e Divirta-se, além da proposta de fechamento de cada unidade chamada de Intervalo.

Em relação à Coleção $\mathrm{B}$, cada volume dessa coleção tem em média 260 páginas e apresenta seis unidades. Cada uma dessas unidades possui dois capítulos para apresentação dos conhecimentos referentes ao ensino de língua. As seções mais frequentes em cada um dos capítulos são: Leitura 1, Leitura 2, Interação entre os textos, Produção escrita e A língua em estudo. Ao final de cada volume é apresentado o item Ampliando seus conhecimentos.

Semelhantemente às coleções anteriores, a Coleção C também apresenta sua sistematização hierárquica. Cada volume tem em média 320 páginas e é composto por quatro unidades temáticas e cada unidade comporta dois capítulos. Nesses capítulos temos as seções Interpretação do texto, Prática de oralidade, Outras linguagens, Língua: usos e reflexão, Produção de texto e Outros textos do mesmo gênero. Ao final de cada exemplar dessa coleção, temos os itens Unidade suplementar e Projeto de leitura.

\section{Recursos tecnológicos mobilizados de forma nuclear ou periférica nas atividades de produção de texto oral}

Encontramos nos LDP duas propostas de produção: entrevista e debate. A entrevista foi apresentada na coleção A e o debate nas coleções A, B e C. Tendo em vista a extensão de um artigo, iremos descrever nesta análise a entrevista e uma das propostas do debate como representantes dos recursos utilizados de forma nuclear e periférica nas atividades.

Para a proposta da entrevista, apresentada na coleção A, o LDP apresenta uma entrevista escrita com a temática cinema para que o aluno conheça o gênero antes da produção, destacando que ele é por natureza um gênero oral. A atividade de produção apresenta diversas orientações ao aluno, como podemos ver nos dois exemplos ilustrados na figura a seguir:

Reúna-se com seus colegas de grupo para, juntos, produzirem uma entrevista oral. Depois de pronta, ela deverá ser exibida aos colegas da classe e posteriormente publicada no jornal mural que o grupo montará no capítulo Intervalo desta unidade. Portanto, será lida também por colegas de outras classes, por professores e funcionários da escola, por seus pais e amigos.

\section{Preparando a entrevista}

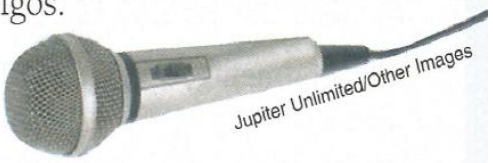

No capítulo Intervalo, vai ser desenvolvido um projeto relacionado com cinema. Por isso, entrevistem uma pessoa ligada a esse assunto, como, por exemplo, um ator, um colecionador de filmes antigos, um proprietário ou funcionário de uma locadora ou de um cinema, ou alguém que simplesmente goste de cinema. Para produzirem uma boa entrevista, procedam assim:

a) Procurem conhecer o entrevistado e decidir qual vai ser o foco da entrevista.

b) Preparem um roteiro de acordo com o perfil do entrevistado. Primeiramente, perguntem seus dados pessoais: nome, idade, cidade onde nasceu, etc. Depois, se o entrevistado for, por exemplo,

Figura 1. Português: linguagens, $7^{\circ}$ ano, São Paulo: Saraiva, 2012, p. 204. 
De acordo com a figura 1, verificamos que a atividade solicita ao aluno para que ele produza uma entrevista oral junto com um grupo de colegas. Essa entrevista, conforme mostra o recorte da atividade na figura 1, será apresentada aos demais alunos da turma e depois será publicada em um jornal para que todos os alunos, professores e funcionários da escola vejam, além dos amigos e pais dos alunos que a produziram. Além disso, a atividade ainda recomenda que o aluno conheça previamente a pessoa que será entrevistada, decidindo o que será focado na entrevista, e prepare um roteiro com o perfil do entrevistado com as suas principais informações para apresentá-lo.

As orientações para a realização desta atividade continuam na próxima página do LDP, como podemos ver na figura 2 a seguir.

\section{Entrevistando}

Não confiem na memória; gravem a entrevista com uma filmadora ou um gravador. Se não dispuserem desses recursos, façam a anotação das respostas. Se possível, fotografem o entrevistado para, posteriormente, juntar algumas fotos dele ao texto da entrevista.

\section{Apresentando a entrevista}

\section{Avaliem a entrevista oral}

Observem se a entrevista apresenta um bom ritmo de perguntas e respostas; se o entrevistador mostra-se simpático e revela ter conhecimento sobre a pessoa entrevistada ou sobre o assunto abordado; se as perguntas são claras; se a linguagem do entrevistador é adequada ao perfil do entrevistado; se o entrevistador conseguiu formular novas perguntas a partir das respostas dadas; se a entrevista é agradável de ouvir e se contém revelações interessantes para o público.

Apresentem à classe a entrevista que fizeram e assistam ou ouçam as dos outros grupos. Depois, com base no boxe Avaliem a entrevista oral, avaliem também as entrevistas dos outros grupos, procurando identificar possíveis falhas para, assim, evitá-las em futuros trabalhos.

Figura 2. Português: linguagens, $7^{\circ}$ ano, São Paulo: Saraiva, 2012, p. 205.

Como mostra a figura 2, recomenda-se que o aluno grave a entrevista, com o auxílio de uma filmadora ou de um gravador (ou smartphone). Essa recomendação mostra que o LDP está levando em consideração nas suas propostas de ensino a utilização de diferentes recursos para a sua realização pelo aluno, o convidando a mobilizar através do uso desses recursos conhecimentos que não são apenas linguísticos pelo fato de eles sozinhos não garantirem a realização da atividade, enveredando pelo paradigma da complexidade. Se o aluno ou o grupo de alunos que está realizando a atividade não tiver acesso a esses recursos digitais, eles devem anotar as respostas utilizando o papel e a caneta.

Realizada a entrevista, a proposta da atividade ainda pede para que a produção seja apresentada a turma, como ainda podemos observar na figura 2. Além disso, ainda sugere que os alunos avaliem a produção e o planejamento, com base no quadro Avaliem a entrevista oral, destacando aspectos importantes e essenciais para a realização de uma entrevista, como a clareza e o ritmo das perguntas, o conhecimento sobre o tema da entrevista por parte do entrevistador, entre outras. Esta tarefa pode ser realizada observando as gravações que foram feitas com o uso dos recursos tecnológicos mencionados. Dessa forma, percebemos que tais recursos não foram utilizados apenas como acessórios para a produção da entrevista, mas como equipamentos necessários à sua realização, pois caso não sejam utilizados esta última parte da atividade (Apresentando a entrevista) não pode ser realizada, conforme a orientação apresentada que diz o seguinte: Apresentem a classe a entrevista que fizeram e assistam ou 
ouçam as dos outros grupos. Depois, com base no boxe Avaliem a entrevista oral, avaliem também as entrevistas dos outros grupos, procurando identificar possíveis falhas para, assim, evitá-las em trabalhos futuros.

Em relação a proposta de produção do debate, apresentada na coleção $B$, vimos que antes da produção do debate, o capítulo do LDP apresenta textos e exercícios de interpretação relacionados a temática da produção. O tema que orienta a produção do debate é o cyberbulling, como podemos ver na figura 3 a seguir:

Um debate só ocorre se o assunto em questão for polêmico, afinal, tal como a dissertação argumentativa, o objetivo do debate é a exposição de argumentos para defender um ponto de vista ou propor uma solução para determinado problema. O tema cyberbullying suscita diversos questionamentos e preocupações. E agora você e seus colegas poderão debater sobre esse tema polêmico e discutir quais são as melhores soluções a serem adotadas para diminuir essa prática.

Seguem algumas instruções para auxiliar a preparação do debate.

" Primeiro, o professor irá dividir a turma em grupos de três pessoas.

- Cada grupo ficará responsável em propor uma solução para diminuir os casos de bullying na internet. Para isso, deverão formular estratégias criativas.

- Para acharem uma boa solução e entenderem melhor o problema, vocês deverão pesquisar sobre o cyberbullying em jornais, revistas e na internet.

- O grupo deverá, então, fazer a

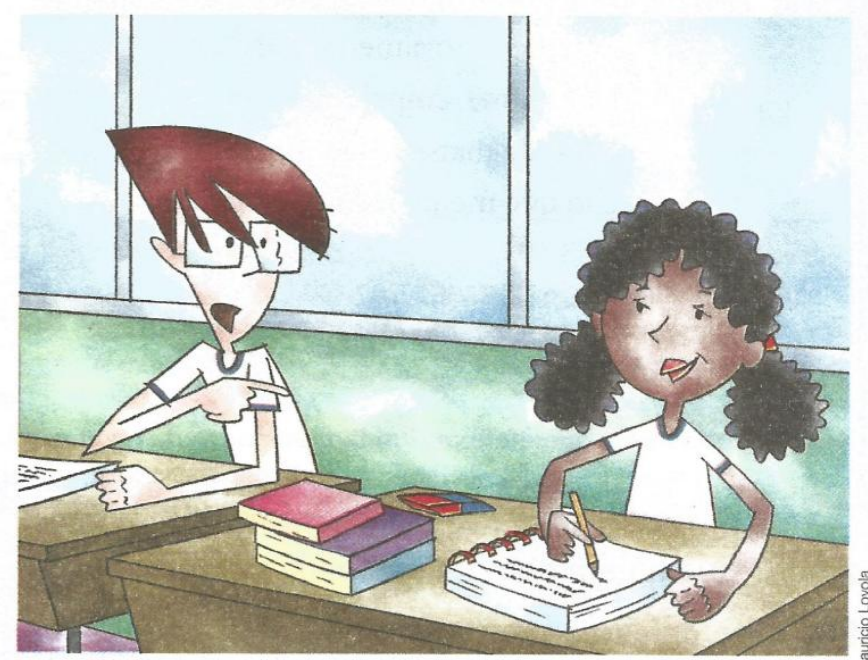
proposta de solução com base nas pesquisas e nos dados coletados, selecionando os melhores argumentos a ser utilizados.

" Em seguida, o grupo escolherá uma pessoa para ser o debatedor, ou seja, aquele que irá expor a proposta de solução formulada pelo grupo.

" O grupo deverá ajudar o debatedor quando necessário, apresentando argumentos e exemplos, ou citando especialistas sobre o assunto, para dar credibilidade à proposta de solução.

- Enquanto os debatedores dos outros grupos expõem os argumentos, o resto da turma fará o papel de público, anotando os argumentos mais importantes ou gravando o debate.

Figura 3. Vontade de saber português, $9^{\circ}$ ano, São Paulo: FTD, 2012, p. 155.

Como podemos observar na figura 3, a proposta de produção da atividade é sucinta e apresenta o tema que será discutido e que o objetivo de um debate é a exposição de argumentos para defender um ponto de vista ou propor uma solução para determinado problema, como ocorre na dissertação argumentativa, que foi trabalhada antes da produção do debate permitindo progressão para o trabalho com a proposta ora apresentada.

Ainda conforme a figura 3 , a atividade apresenta instruções para a realização do debate que será produzido pelos alunos. Nessas instruções, a atividade diz que o professor deve organizar a turma em grupos de três pessoas para que em seguida cada grupo apresente uma solução para reduzir os casos de bullying na internet. Para isso, os alunos podem pesquisar sobre o assunto em jornais, revistas e sites. A partir da leitura dessas instruções, já 
identificamos o uso do computador como recurso que pode ser utilizado como auxílio, como suporte para a busca de informações para a produção do debate.

A última instrução apresentada na figura 3 refere-se à possibilidade de uso do gravador para registrar o debate quando diz que "enquanto os debatedores dos outros grupos expõem os argumentos, o resto da turma fará o papel de público, anotando os argumentos mais importantes ou gravando o debate". Nesta atividade, percebemos que o recurso gravador é utilizado de forma periférica, pois a sua não utilização não implica em nenhum dano à realização da atividade proposta. A atividade de produção do debate na coleção $\mathrm{C}$ foi semelhante a essa, utilizando o recurso de forma periférica.

Observando as atividades analisadas, percebemos que as propostas se direcionam para o paradigma da complexidade. Isso porque o agir nas atividades apresentadas envolvem conhecimentos extra-disciplinares para realizá-las (neste caso, conhecimentos advindos de outras que não de língua portuguesa), como conhecimentos técnicos, para a utilização de diversos recursos, como o computador, o gravador e a filmadora.

Essa compreensão também nos autoriza a dizer que o saber sobre a língua por si só nas atividades descritas não é suficiente para garantir-lhes a realização, sendo necessário a mobilização de diversos conhecimentos da parte dos alunos para a execução das atividades descritas através do uso dos recursos tecnológicos.

Dessa forma, a complexidade das atividades ainda deve ser tomada em relação ao sujeito que o produz, neste caso, o aluno, e os conhecimentos (linguísticos e técnicos) adquiridos por ele. Uma mesma atividade pode ter níveis de complexidade diferentes dependendo do sujeito que a irá realizar, das suas ações procedimentais e dos recursos que serão utilizados para o seu planejamento e realização.

Por exemplo, o aluno que não tem acesso a alguns dos recursos tecnológicos verificados nas atividades dos LDP provavelmente não irá realizá-la como aquele aluno que utiliza esses recursos cotidianamente em diversas situações e diversos lugares que não a escola, o que de certa forma o torna mais preparado, pelo menos tecnicamente, para realizar essas atividades que foram propostas pelos LDP.

Além disso, uma outra consideração importante a se fazer a respeito dessas atividades é que os recursos utilizados em suas realizações não fazem parte de insinuações fortuitas, apresentadas aleatoriamente pelos autores dos LDP para a realização das atividades apenas para utilizá-los sem nenhum objetivo, finalidade ou propósito, mas de orientações oficiais de ensino vigentes neste país que podem ser visualizadas tanto nos documentos que já estão consagrados na área de ensino (PCN, 1998) quanto naqueles que ainda estão em fase de elaboração (BNCC) pelo governo federal através do Ministério da Educação para a parametrização do ensino.

\section{Considerações finais}

Tendo em vista a questão de pesquisa desse trabalho e os objetivos delimitados, verificamos que as atividades de produção de textos orais nos LDP mobilizam o uso dos recursos tecnológicos de duas formas: nuclear ou periférica. Na primeira forma, o recurso tem centralidade na realização da atividade, tornando-se indispensável para a sua realização, enquanto que na segunda forma ele é utilizado de modo periférico, sendo dispensável na realização da atividade.

Tal constatação nos mostra que a lógica do paradigma da complexidade está no cerne das propostas das atividades apresentadas pelos LDP. Isso porque as atividades ao incorporarem o uso de diversos recursos demandam a mobilização de conhecimentos que não apenas linguísticos para a sua realização, mostrando que o saber sobre a língua não é suficiente por si só para garantir-lhes a realização. Esse resultado nos impulsiona para uma 
nova fase de pesquisa, já em execução, sobre as reais possibilidades de inclusão e utilização dos recursos tecnológicos nas práticas escolares da educação básica.

\section{Referências}

ALVES, R.; BRUGNEROTTO, T. Vontade de saber português. São Paulo: FTD, 2012. BORGATTO, A. M. T.; BERTIN, T. C. H.; MARCHEZI, V. L. C. Projeto teláris: português. São Paulo: Ática, 2012.

. Secretaria de Educação Fundamental. Parâmetros curriculares nacionais: terceiro e quarto ciclos do ensino fundamental: língua portuguesa. Brasília: MEC/SEF, 1998.

- Secretaria de Educação Básica. Base Nacional Comum Curricular (versão preliminar). Brasília: MEC, 2017.

BUNZEN, C. Dinâmicas discursivas na aula de português: usos do livro didático e projetos didáticos autorais. 2009. 227 f. Tese (Doutorado em Linguística Aplicada) - Programa de Pós-Graduação em Linguística Aplicada, Universidade Estadual de Campinas, São Paulo, 2009.

CEREJA, W. R.; MAGALHÃES, T. C. Português: linguagens. São Paulo: Saraiva, 2012.

CORTELLA, M. S. Paradigmas da tecnologia e a distração. In: Educação, escola e docência: novos tempos, novas atitudes. São Paulo: Cortez, 2014.

CELANI, M. A. A. A relevância da linguística aplicada na formulação de uma política educacional brasileira. In: FORTKAMP, M. B. M. (Org.). Aspectos da linguística aplicada: estudos em homenagem ao professor Hilário Inácio Bohn. Florianópolis: Insular, 2000.

DIONÍSIO, A. P.; BEZERRA, M. A. O livro didático de português: múltiplos olhares. Rio de Janeiro: Lucerna, 2005.

EGITO, G. A.; RAFAEL, E. L. O livro didático de português: formas de utilização de tecnologias. Relatório de Pesquisa. Campina Grande: UFCG/PIBIC, circulação restrita, 2014.

Tecnologia em manuais do professor de livros didáticos de português. Relatório de Pesquisa. Campina Grande: UFCG/PIBIC, circulação restrita, 2015.

Recursos tecnológicos em atividades de leitura e de produção de textos no livro didático de português. Relatório de Pesquisa. Campina Grande: UFCG/PIBIC, circulação restrita, 2016.

FREIRE, M. M.; LEFFA, V. J. A auto-heteroecoformação tecnológica. In: MOITA LOPES, L. P. (Org.). Linguística aplicada na modernidade recente. São Paulo: Parábola, 2013.

GERALDI, J. W. O texto na sala de aula. Cascavel: Assoeste, 1984.

. Portos de passagem. São Paulo: Martins Fontes, 1991.

KENSKI, V. M. Educação e tecnologias: o novo ritmo da informação. 8. ed. Campinas: Papirus, 2012.

KUHN, T. S. A estrutura das revoluções científicas. 4. ed. São Paulo: Perspectiva, 1996.

LE GOFF, J. História e memória. Tradução Bernardo Leitão (et al). Campinas, São Paulo: Editora da UNICAMP, 1990. Disponível em <http://memorial.trt11.jus.br/wpcontent/uploads/Hist\%C3\%B3ria-e-Mem\%C3\%B3ria.pdf>. Acesso em: 29 de agosto de 2016.

LEONTIEV, A. N. Actividad, conciencia, personalidad. La Habana: Editorial Pueblo y Educación, 1983. 
LINO DE ARAÚJO, D.; SILVA, W. M. Oralidade em foco: conceito, descrição e experiências de ensino. Campina Grande: Bagagem, 2013.

LUCKESI, C. C. Avaliação da aprendizagem escolar: estudos e proposições. 22. ed. São Paulo: Cortez, 2011.

MATÊNCIO, M. L. Estudo da língua falada e aula de língua materna: uma abordagem processual da interação professor/alunos. Campinas: Mercado das Letras, 2001.

MARCUSCHI, L. A. Da fala para a escrita: atividades de retextualização. 4. ed. São Paulo: Cortez, 2003.

MOITA LOPES, L. P. Fotografias da linguística aplicada brasileira na modernidade recente: contextos escolares. In: (Org.). Linguística aplicada na modernidade recente. São Paulo: Parábola, 2013.

MOREIRA, H; CALEFFE, L. G. Metodologia da pesquisa para o professor pesquisador. Rio de Janeiro: DP\&A, 2008.

MORAES, M. C. O paradigma educacional emergente. Campinas: Papirus, 1997.

RAFAEL, E. L. Relações entre componentes da prática escolar e de práticas não escolares. Fórum Linguístico, Florianópolis, v. 14, n. 1, p. 1823-1838, 2017.

ROJO, R. H. R.; BATISTA, A. A. G. (Org.). Livro didático de língua portuguesa, letramento e cultura da escrita. Campinas: Mercado das Letras, 2003.

SIGNORINI, I. Do residual ao múltiplo e ao complexo: o objeto da pesquisa em Linguística Aplicada. In: SIGNORINI, I.; CAVALCANTI, M. C. (Orgs.). Linguística aplicada e transdisciplinaridade: questões e perspectivas. Campinas: Mercado de Letras, 1998.

. Letramento e inovação no ensino e na formação do professor de língua portuguesa. In: - Significados da inovação no ensino de língua portuguesa e na formação de professores. Campinas: Mercado de Letras, 2007.

SCHNEUWLY, B.; DOLZ, J. Gêneros orais e escritos na escola. São Paulo: Mercado de Letras, 2004.

TARDIF, M. Saberes docentes e formação profissional. 17. ed. Petrópolis: Vozes, 2014.

VASCONCELLOS, M. J. E. Pensamento sistêmico: o novo paradigma da ciência. Campinas: Papirus, 2002. 